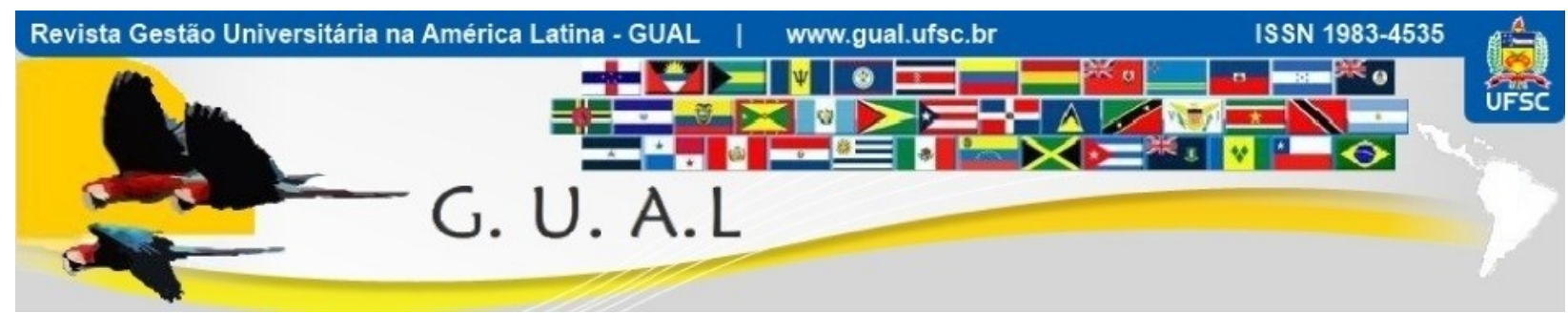

DOI: https://doi.org/10.5007/1983-4535.2021.e79018

\title{
ASSÉDIO MORAL E SEXUAL NO SERVIÇO PÚBLICO: CARACTERÍSTICAS E REFLEXOS NOS PEDIDOS DE REMOÇÃO EM UMA INSTITUIÇÃO DE ENSINO SUPERIOR DA REGIÃO NORTE DO BRASIL
}

\author{
MORAL AND SEXUAL HARASSMENT IN PUBLIC SERVICE: \\ CHARACTERISTICS AND REFLEXES IN THE REQUESTS FOR REMOVAL IN A \\ HIGHER EDUCATION INSTITUTION OF THE NORTHERN REGION OF BRAZIL
}

Dielly Débora Farias Fonseca, Mestre https://orcid.org/0000-0002-6118-7142 diellyfarias@ufpa.br

Universidade Federal do Pará | Secretaria Executiva Belém | Pará | Brasil

Carlos André Corrêa de Mattos, Doutor http://orcid.org/0000-0002-3027-7479 carlosacmattos@hotmail.com

Universidade Federal do Pará | Programa de Pós-Graduação em Administração Belém | Pará | Brasil

\begin{abstract}
Alessandro de Castro Corrêa, Doutor https://orcid.org/0000-0001-6632-3230 alessandro.correa4@gmail.com Instituto Federal de Educação, Ciência e Tecnologia do Pará | Programa de Pós-Graduação em Engenharia de Materiais Belém | Pará | Brasil
\end{abstract}

Recebido em 05/janeiro/2021

Aprovado em 03/junho/2021

Publicado em 01/setembro/2021

Sistema de Avaliação: Double Blind Review

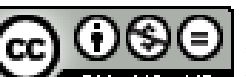

Esta obra está sob uma Licença Creative Commons Atribuição-Uso. 


\title{
RESUMO
}

O objetivo deste estudo foi analisar a presença e as características do assédio moral e sexual em uma Instituição Federal de Ensino Superior da Região Norte do Brasil e, assim, mensurar seus reflexos nos pedidos de remoção. Para tanto, foi feita uma pesquisa de campo com a utilização de questionário. A amostra foi probabilística aleatória simples e resultou em 251 entrevistados. $\mathrm{O}$ tratamento de dados foi quantitativo e utilizou análise fatorial exploratória (AFE) e regressão linear múltipla (RLM). A análise fatorial captou a presença de quatro fatores, que explicaram $66,05 \%$ da variância. Os fatores foram induzir ao erro $(19,52 \%)$, desqualificar (16,53\%), isolar e recusar comunicação (16,50\%) e agressão verbal, física e sexual (13,50\%). A regressão linear múltipla revelou que $20 \%$ da variância dos pedidos de remoção eram explicados pelo assédio. A conclusão reforça a necessidade de políticas de esclarecimento e combate ao assédio moral e sexual na instituição.

Palavras-chave: Violência. Instituições de Ensino. Gestão de Pessoas. Poder.

\begin{abstract}
The objective of this study was to analyze the presence and characteristics of bullying and sexual harassment in a Federal Higher Education Institution of Northern Brazil, and thus measure its effects on removal requests. Therefore, a field survey was conducted using a questionnaire. The sample was simple random probability and resulted in 251 respondents. Data processing was quantitative and used exploratory factor analysis (EFA) and multiple linear regression (MLR). Factor analysis has detected the presence of four factors, which explained $66.05 \%$ of the variance. The factors were defined as mislead $(19.52 \%)$, disqualify $(16.53 \%)$, isolate and deny communication $(16.50 \%)$ and verbal, physical and sexual aggression (13.50\%). Multiple linear regression showed that $20 \%$ of the variance of removal requests were due to harassment. The conclusion reinforces the need for policies to clarify and combat moral and sexual harassment in the institution.
\end{abstract}

Keywords: Violence. Educational Institutions. People Management. Power. 


\section{INTRODUÇÃO}

O trabalho é um aspecto fundamental para a vida em sociedade, e a interação entre os trabalhadores e o local de trabalho tem reflexos em diversos aspectos da vida humana. No âmbito organizacional, a relação entre o trabalhador e o ambiente de trabalho repercute fortemente em aspectos valorizados pelas organizações como motivação, comprometimento, satisfação no trabalho, engajamento, produtividade, entre outros. No âmbito pessoal, o trabalho é capaz de influenciar na forma como os trabalhadores se percebem e como eles são percebidos em suas relações pessoais e sociais (HERZBERG, 1966; 1980; 1996).

Assim, apesar de o trabalho ser, essencialmente, um dos aspectos da valorização humana, muitas vezes ele se constitui em relações conflituosas, manifestações de preconceitos e, por vezes, assume formas violentas. Nesse sentido, a preocupação com a violência no ambiente de trabalho assumiu maior destaque a partir do final do século $\mathrm{XX}$, ocasião que passou a integrar mais frequentemente as preocupações organizacionais. Freitas (2001) destaca que, gradativamente, o debate sobre a violência no ambiente organizacional ganhou contornos científicos, tanto para identificar suas causas, quanto para encontrar alternativas de prevenção e controle.

Classificado entre as formas de violência, o assédio moral e sexual constitui parte do estrato negativo das relações de trabalho e pode ser entendido como reflexo da omissão da gestão organizacional, por vezes, igualmente violenta, ou que tem mal ou pouco definidos os valores que orientam sua conduta. A violência discriminatória traz graves prejuízos pessoais e organizacionais, uma vez que, mesmo quando direcionada a uma única pessoa, o clima hostil provocado pelo assédio se reflete negativamente nos demais trabalhadores e acaba por atingir a organização pela contaminação do ambiente de trabalho. Hirigoyen $(2000$, p.17) conceitua assédio moral como:

[...] qualquer conduta abusiva, manifestando-se, sobretudo, por comportamentos, palavras, atos, gestos, escritos que possam trazer dano à personalidade, à dignidade ou à integridade física ou psíquica de uma pessoa, pôr em perigo seu emprego ou degradar o ambiente de trabalho.

Por outro lado, o assédio sexual é reconhecido pela União Europeia como uma forma de discriminação que ocorre sempre que se observa "[...] um comportamento indesejado de carácter sexual [...] com o objetivo ou o efeito de violar a dignidade da pessoa, em especial, quando cria um ambiente intimidativo, hostil, degradante, humilhante ou ofensivo" (JORNAL DA UNIÃO EUROPEIA, 2014, p.40). Estudos de Freitas (2007), Guedes (2008), Hirigoyen 
(2006) e Mattos et al. (2010), entre outros, destacam que algumas organizações equivocadamente fomentam a ideia de que a competitividade entre seus integrantes proporcionará maior desempenho individual e coletivo. Assim, o uso descompassado de práticas voltadas para a busca pela excelência profissional pode servir como justificativa para que comportamentos perversos e hostis passem a integrar o cotidiano da organização.

Desta forma, aprofundar estudos com foco no assédio moral e sexual pode contribuir para a formulação de estratégias que informem, orientem, discutam, coíbam e punam práticas violentas que atentem contra a dignidade humana, especialmente aquelas de cunho perverso. Discutir o assédio moral e o assédio sexual no âmbito organizacional pode fomentar a consolidação de condutas pautadas na moral e em princípios éticos que permitam distinguir posturas esperadas daquelas não aceitas pela organização.

Por outro lado, Caran et al. (2010) complementam e destacam que os casos de assédio nas organizações privadas são normalmente mais perceptíveis, geralmente perduram por menor tempo e finalizam com a demissão do assediado. Entretanto, os mesmos autores lembram que nas organizações públicas a violência assediosa pode durar anos em decorrência da estabilidade, aspecto que, em certa medida, acaba por proteger o agressor, forçando o assediado a tentar uma remoção para outro setor ou departamento ou ainda a se conformar com sua condição, o que fatalmente levará ao adoecimento e, muitas vezes, à opção pelo desligamento da organização.

Nesse contexto, o presente estudo concentrou-se em analisar a presença e as características do assédio moral e sexual em uma Instituição Federal de Ensino Superior da Região Norte do Brasil e, assim, mensurar seus reflexos nos pedidos de remoção. Desta forma, o problema de pesquisa que orientou a investigação foi: quais são as características do assédio moral e sexual na instituição pesquisada e como ele influencia os pedidos de remoção? O caráter inovador deste estudo está em sistematizar informações que busquem mensurar os reflexos do assédio moral e sexual na movimentação interna de pessoal, o que impacta, em certa medida, em novos processos de socialização e mais gastos com treinamento e desenvolvimento de pessoal.

Os resultados possibilitaram caracterizar o assédio moral e sexual em quatro fatores denominados "Induzir ao erro" (fator principal), "Desqualificar", "Isolar e Recusar Comunicação" e "Violência Verbal, Física e Sexual" e constar que há uma associação positiva entre a ocorrência do assédio moral e sexual e a movimentação de pessoal por meio 
dos pedidos de remoção. Esses aspectos justificam as políticas de combate e prevenção ao assédio moral e sexual como uma forma de proporcionar um ambiente de trabalho mais produtivo, ético e que seja capaz de refletir uma perspectiva moderna da atividade laboral.

\section{REFERENCIAL TEÓRICO}

\subsection{ASSÉDIO MORAL: ORIGEM, EVOLUÇÃO E CARACTERÍSTICAS.}

A violência no ambiente de trabalho remonta à antiguidade, com o início da exploração do homem como força de trabalho. Entretanto, conforme Costa et al. (2015), os estudos sobre assédio moral identificado como forma de violência ganharam força nos países desenvolvidos somente no final do século XX, quando passaram a ser compreendidos como ação destruidora das relações de trabalho, do trabalhador e das organizações. Entretanto, para que o assédio moral fosse reconhecido como uma forma de violência organizacional e sua manifestação caracterizada como tal, foi necessário um longo período de amadurecimento, observado desde meados da década de 1970.

Conforme Einarsen, Nielson e Glase (2017), o primeiro trabalho, em que podem ser reconhecidas características de estudos científicos sobre assédio moral, é a obra intitulada " $\mathrm{O}$ trabalhador assediado", da psiquiatra norte-americana Carroll Brodsky (BRODSKY, 1976). Neste trabalho, a pesquisadora definiu o assédio como um tratamento repetido, contínuo e persistente, a fim de atormentar e perseguir o outro para intimidá-lo. Contudo, até então, pouco se conhecia quanto aos prejuízos potenciais do assédio moral para os valores de um grupo, e a discussão não avançou em termos de gestão organizacional (EINARSEN; NIELSEN; GLASØ, 2017), uma vez que a pesquisa de Brodsky (1976) se concentrava nas condições sociomédicas do trabalho, motivada pela então recente promulgação dos direitos trabalhistas na Suécia.

Estruturadas as dimensões do assédio, os estudos que introduziram a perspectiva moral foram apresentados anos mais tarde, já na década de 1990, pelo psicólogo sueco Heinz Leymann, pesquisador na área da psicologia do trabalho. Leymann (1990) identificou uma forma de violência, com características coercitivas, a qual identificou como "psicoterror" (MATTOS et al., 2010), com características mais abrangentes, o mesmo autor classificou como violência o uso de comunicação hostil e não ética, originada por um ou mais indivíduos e dirigida de forma sistemática a um indivíduo especificamente. Assim, o assediado era 
colocado em uma condição desprotegida, essencialmente indefeso e condicionado a permanecer nesta situação de submissão pelas ações hostis (LEYMANN, 1990; 1996).

Os estudos de Leymann $(1990 ; 1996)$ fizeram com que a expressão mobbing ganhasse força nos países europeus como o equivalente ao que se conhece hoje como assédio moral. Helonai (2004) destaca que essa expressão provavelmente começou a ser utilizada bem antes dos trabalhos de Leymann, por volta da década de 1960, pelo zoólogo austríaco Konrad Lorens, que utilizou a expressão para designar comportamentos agressivos utilizados por animais, com o intuito de expulsar um membro indesejado do grupo.

Com a evolução dos estudos, o assédio moral passou a receber atenção de diversas áreas das ciências, especialmente a partir dos trabalhos publicados pela psiquiatra francesa Marie-France Hirigoyen, que até hoje se posiciona como umas das principais referências no estudo do assédio moral. No ano de 1998, na obra "Le Harcèlement moral: la violence perverse au quotidien", ela ampliou e sistematizou a compreensão do assédio moral (HIRIGOYEN, 2000).

No Brasil, os estudos voltados a essa forma de violência se intensificaram com a publicação da dissertação de mestrado da médica Margarita Barreto, no ano de 2000, intitulada "Uma jornada de humilhações" (BARRETO, 2000). Este estudo, com amostra pouco superior a 2000 trabalhadores de indústrias no Estado de São Paulo, apresentou resultados preocupantes até então desconhecidos. Entre os resultados, $42 \%$ dos entrevistados relataram histórias de humilhações no trabalho, tendo sido as mulheres as que apresentaram a maior frequência, pois $65 \%$ delas relataram alguma experiência humilhante e degradante no expediente de trabalho. Barreto (2004) destaca que o assédio moral é mais comum nas relações hierárquicas autoritárias, assimétricas e não éticas, o que resulta na desestabilização do tripé trabalhador, ambiente de trabalho e organização.

Costa et al. (2015) reforçam que, em razão da multiplicidade do alcance do assédio moral em termos de diversas áreas do conhecimento como medicina, psicologia, psiquiatria, direito e administração, a definição de um conceito completo para o assédio moral ainda não pôde ser feita, visto ainda haver um vasto campo de estudo a ser explorado, e suas consequências ainda não foram elencadas plenamente.

As causas que desencadeiam o assédio moral são desconhecidas, contudo, como destacam Hirigoyen (2000) e Barreto (2003), o assédio pode originar-se por inveja, preconceito, ciúme, competitividade, individualismo ou ainda rivalidade, fomentada pela 
própria organização, e agravada pela instabilidade no emprego. O certo é que todos aqueles que diferem do grupo são vítimas em potencial, não importando as condições pelas quais ele se diferencia, seja pela cor, sexo, escolaridade, cultura, potencial de trabalho, salário, idade, opção sexual, limitações físicas, entre outras. O que faz com que o indivíduo seja alvo do assédio é sua singularidade confrontada com o desvio comportamental do agressor (HIRIGOYEN, 2000; BARRETO, 2003).

Heloani e Barreto (2015) afirmam que a falta de solidariedade gerada pela disputa de espaços resulta em um espiral de competitividade estimulada pela busca da estabilidade e da colocação no mercado de trabalho. A injúria, o estresse, o medo de ser demitido e o controle passam a ser o resultado natural de um mercado extremamente competitivo, podendo levar ao surgimento e ao agravamento do assédio moral na organização. Portanto, quando a organização normatiza a conduta de seus integrantes, possibilita que os gestores respaldem seus atos de forma objetiva, o que diminui a possibilidade de interpretações variadas. Nesse sentido, a falta de esclarecimento dificulta a identificação de práticas assediosas pelo simples desconhecimento, fragilizando ainda mais o assediado (FITZGERALD; ORMEROD, 1991).

\subsection{ASSÉDIO SEXUAL NO TRABALHO}

Por outro lado, o assédio sexual por vezes é confundido com uma "cantada" e pode ser compreendido a princípio como um episódio com nenhuma ou baixa gravidade. Entretanto, Freitas (2001), ao tratar da temática, diferencia a "cantada" do assédio sexual. Para a autora, a primeira seria uma proposta habilidosa que tem por objetivo convencer o outro, com base na sedução, a aceitar as investidas do interessado. Já o assédio sexual assume cunho autoritário, perverso, que tem a punição como forma de coerção. Quanto aos comportamentos que constituem o assédio sexual no trabalho, podem-se considerar anedotas, conversas sexuais, favores sexuais, voyeurismo, ambiente pornográfico e contato físico não desejado (DEUTSCHMAN, 1991; DIAS, 2008). Assim, a perseguição à vítima ocorre de maneira ostensiva por meio de ofensas, telefonemas insistentes, presentes, perseguição na rua e em ambientes frequentados por ela (NOBREGA, 2016), podendo chegar a comportamentos extremados de abuso sexual, sendo este o resultado final e mais grave do assédio sexual (DIAS, 2008).

Costa (1995) aborda as vantagens oferecidas na troca sexual como promoções, aumento salarial e estabilidade. A pesquisadora considera em seus estudos desde as formas 
sutis (olhar e fala) até as punições quando ocorrem negativas, como a demissão e a violência física. O risco de permanência no emprego ocorre não somente pela ameaça direta, mas também de forma indireta, pelo ataque ao bem-estar no trabalho.

A Organização Internacional do Trabalho (2001, p. 41) define assédio sexual como uma "[...] conduta insistente, persecutória, que, ao visar a obter favores sexuais, resulta por violar a liberdade sexual" e amplia essa noção quando acrescenta o conceito de liberdade sexual como "[...] noção de livre disposição do corpo, amparada na esfera dos direitos de liberdade, que se apresentam como bens jurídicos constitucionalmente assegurados" (p.47). Assim, a violação desse direito deixa de ser um problema apenas entre as duas partes (assediador e assediado) e passa a agredir os direitos assegurados a todo cidadão.

Quando o assédio assume dimensão sexual, ele se constitui numa violência materializada pelo exercício do poder, seja hierárquico, de gênero ou econômico (COSTA, 1995; ORGANIZAÇÃO INTERNACIONAL DO TRABALHO, 2001; DIAS, 2008; PINA; PAGE, 2015; NÓBREGA, 2016; BENDIXEN; KENNAIR, 2017). Destaca-se que Brito (2011) e a Organização Internacional do Trabalho (2001) deixam claro que a investida sexual correspondida de forma recíproca não configura assédio sexual. Por esta razão, é fundamental para que se configure assédio a ação indesejada persistente, respondida pela vítima com repúdio aos atos assediosos.

O assédio sexual pode ser classificado em duas formas: (1) o assédio sexual por intimidação ou ambiental, caracterizado pela criação de um ambiente sexualizado, instalandose, assim, um clima hostil e intimidador (ORGANIZAÇÃO INTERNACIONAL DO TRABALHO, 2001; MEJÍAS GARCIA, 2001; BRITO, 2011; MORAIS; MÚRIAS; MAGALHÃES, 2014) e (2) o assédio sexual por chantagem ou qui pro quo, caracterizado pela existência da hierarquia e autoridade nas relações de trabalho (ORGANIZAÇÃO INTERNACIONAL DO TRABALHO, 2001; BRITO, 2011; PIERUCCI et al., 2014)

Quando o assédio sexual ocorre por intimidação ou ambiental, observa-se uma disputa de espaço profissional, entretanto o assediador utiliza o assédio sexual em vez do moral quando o assediado é uma pessoa fragilizada na organização ou socialmente, na maioria das vezes, mulheres e homossexuais. Outra característica do assédio sexual por intimidação é que a relação de poder no sentido hierárquico não é uma condição sine qua non para ocorrência dessa forma de assédio (ORGANIZAÇÃO INTERNACIONAL DO TRABALHO, 2001; MORAIS; MÚRIAS; MAGALHÃES, 2014). 
No assédio sexual por intimidação, a violência é caracterizada pelo ataque à liberdade de negar as ações sexistas. Ressalta-se também que, nesta forma de assédio, a vítima não necessariamente sofre punições ou tem sua posição de trabalho prejudicada. Sendo assim, o assédio sexual por intimidação é habitualmente praticado por colegas de trabalho (PIERUCCI et al., 2014), constituído como ilícito civil, trabalhista e administrativo (BRITO, 2011).

Já o assédio sexual por chantagem ou qui pro quo se caracteriza pela presença da hierarquia e autoridade nas relações de trabalho (ORGANIZAÇÃO INTERNACIONAL DO TRABALHO, 2001; BRITO, 2011; PIERUCCI et al., 2014). Para a Organização Internacional do Trabalho (2001) e Brito (2011), a ameaça à condição de trabalho, econômica e moral condiciona a vítima à compreensão de que, caso não aceite, sofrerá prejuízos materiais, e caso aceite, terá vantagens profissionais que estão condicionadas exclusivamente ao seu consentimento.

Essa modalidade de assédio configura crime tipificado no Código Penal Brasileiro (BRASIL, 1940) desde o ano de 2001, a partir da promulgação da Lei No. 10.224, de 15 de maio de 2001 (BRASIL, 2001), que alterou o decreto-lei de no. 2.848, de 7 de dezembro de 1940, no seu artigo 216-A, com o preenchimento da exigência de se considerar "[...] $]$ superior hierárquico ou ascendência inerentes ao exercício de emprego, cargo ou função" (BRASIL, 1940).

No Brasil, o assédio sexual só é considerado crime quando ocorre no ambiente de trabalho e se praticado por superior hierárquico. Conforme Art. 216-A do Código Penal Brasileiro (BRASIL, 1940), ele se legitima como forma de conseguir vantagem ou favorecimento sexual pela condição de poder instituída pelo fato de o assediador desempenhar cargo de superior hierárquico ou que releve alguma forma de ascendência decorrente de cargo ou função que o coloque em condição de poder sobre a vítima. Contudo, mesmo não caracterizando crime, o assédio sofrido por colega de trabalho, cliente ou subordinado é um problema real no ambiente corporativo.

Nesse contexto, Freitas (2005, p. 15) refere-se à "saúde moral” da organização como um comportamento crítico permanente quanto às práticas das organizações e de seus trabalhadores, norteadas por compromissos e princípios éticos, justos e íntegros, capazes de atingir toda a rede de relacionamentos organizacionais - trabalhadores, concorrentes e sociedade. Assim, o papel exercido pela organização passa a ser condicionante para a redução dos casos de assédio sexual. Pesquisas relacionadas com a conduta e os valores das 
organizações (HULIN; FITZGERALD; DRASGOW, 1996; FITZGERALD et al., 1997; PRYOR; MEYERS, 2000; WILLNESS; STEEL; LEE, 2007; PINA; PAGE, 2015) mostram que a tolerância no ambiente organizacional favorece o assédio sexual e sua repetição. Por outro lado, organizações que têm políticas de intolerância a comportamentos abusivos inibem a atuação de assediadores assim como estimulam a vítima a se defender, sem temer retaliações.

Portanto, tal como ocorre no assédio moral, o agressor pode encontrar no ambiente organizacional grupos que confirmem essas práticas assediosas. Tendo o anonimato como proteção à sua ação, cria-se um ambiente hostil e abusivo (PRYOR; MEYERS, 2000; PINA; PAGE, 2015), no qual a responsabilidade é difusa, fazendo com que o crime não seja pertencente a um único criminoso, mas a um comportamento aceitável de uma coletividade (CHAMBERLAIN et al., 2008; PINA; PAGE, 2015).

Burges e Borgida (1997) complementam e destacam que, considerando a crença de que as mulheres no ambiente corporativo não são somente colegas de trabalho, mas potenciais parceiras sexuais, perspectiva agravada em um ambiente de trabalho no qual a sexualidade não é controlada, o assédio é visto como algo natural. Para a Organização Internacional do Trabalho (ORGANIZAÇÃO INTERNACIONAL DO TRABALHO, 2001), o assédio sexual é um componente que influencia diretamente a igualdade de oportunidades entre homens e mulheres, uma vez que se sustenta na estrutura social de poder e como tal deve ser combatido.

\section{METODOLOGIA}

Conforme Gil (2014), este estudo é classificado como uma investigação descritiva, feita na forma de levantamento, com amostragem probabilística e tratamento quantitativo de dados. O universo de pesquisa foi formado por servidores públicos, lotados em uma Instituição de Federal de Ensino Superior na Região Norte do Brasil, composto por técnicos administrativos e docentes, ocupantes ou não de cargos de gestão, perfazendo ao todo 5.408 servidores. A amostragem foi probabilística aleatória simples, conforme a Fórmula 1 (GIL, 2014), sendo calculada com $90 \%$ de margem de segurança e $6 \%$ de erro, o que resultou em 251 questionários de pesquisa válidos:

$$
n=\frac{\sigma^{2} \cdot p \cdot q \cdot N}{e^{2}(N-1)+\sigma^{2} \cdot p \cdot q}
$$


Em que $n=$ tamanho da amostra; $\sigma^{2}=$ nível de confiança (em número de desvios padrão); $\mathrm{p}$ = percentagem com qual o fenômeno se verifica; $\mathrm{q}$ = percentagem complementar; $\mathrm{N}=$ tamanho da população; e $\mathrm{e}^{2}=$ erro amostral ao quadrado.

Os dados foram obtidos com a utilização de questionário organizado em duas seções: a primeira reuniu informações sociodemográficas dos entrevistados como idade, escolaridade, cargo, estado civil, experiência profissional, entre outras; a segunda foi formada por 44 afirmativas que caracterizaram formas de assédio moral e sexual com respostas em escala de Likert com dez itens, estendendo-se entre um (1) para nunca acontece até dez (10) para sempre ocorre. A pesquisa foi aprovada pelo comitê de ética em pesquisas com seres humanos pelo protocolo CAAE: 79380217.0.0000.0018.

O tratamento de dados utilizou técnicas multivariadas, sendo selecionadas a análise fatorial exploratória (AFE) para a identificação das características do assédio moral e a regressão linear múltipla (RLM) para verificar a associação entre o assédio, moral e sexual, e os pedidos de remoção. Procurou-se assim observar relações de dependências entre as variáveis e, portanto, identificar se havia ou não relação entre os pedidos de remoção e a ocorrência do assédio. A análise fatorial, conforme Hair et al. (2009), é uma técnica de análise de dados, classificada entre as técnicas de interdependência, que se destaca pela capacidade de sumarizar grande volume de dados em reduzido número de fatores ou variáveis latentes. A análise fatorial pode ser expressa pela Fórmula 2 (DILLON; GOLDSTEIN, 1984):

$$
\mathrm{X}=\alpha \mathrm{F}+\varepsilon,
$$

Em que $X$ é o p-dimensional, vetor transposto das variáveis observáveis, denotado por $\mathrm{X}$ $=\left(\mathrm{x}_{1}, \mathrm{x}_{2} \ldots, \mathrm{x}_{\mathrm{p}}\right)^{\mathrm{t}} ; \quad F$ é o q-dimensional, vetor transposto das variáveis não observáveis ou variáveis latentes, identificados como fatores comuns, expressos por $F=\left(f_{1}, f_{2}, \ldots, f_{q}\right)^{t}$, sendo $\mathrm{q}<\mathrm{p}$; $\varepsilon$ é o p-dimensional, vetor transposto de variáveis aleatórias ou fatores únicos, $\varepsilon=\left(\mathrm{e}_{1}\right.$, $\left.\mathrm{e}_{2}, \ldots, \mathrm{e}_{\mathrm{p}}\right)^{\mathrm{t}}$; e $\alpha$ é a matriz (p, q) de constantes desconhecidas, denominadas "cargas fatoriais".

Neste estudo, foram utilizados os escores fatoriais que, conforme Hair et al. (2009), podem substituir as variáveis originais e são expressos pela combinação linear mostrada na Fórmula 3 (DILLON; GOLDSTEIN, 1984), em que, para cada fator $\boldsymbol{f}_{j}$, o i-ésimo escore fatorial é definido por $F_{i j}$ :

$$
F_{i j}=b_{1} x_{i 1}+b_{2} x_{i 2}+\ldots+b_{p} x_{i p} ; i=1,2, \ldots, n ; \quad j=1,2, \ldots, p
$$

Em que $b_{i}$ são os coeficientes de regressão estimados para os $n$ escores fatoriais comuns; e $x_{i j}$ são as $n$ observações das $p$ variáveis observáveis. 
Quanto à regressão linear múltipla (RLM), é uma técnica de dependência utilizada para "estimar uma função matemática que busca descrever o comportamento de determinada variável, denominada dependente, com base nos valores de uma ou mais variáveis, denominadas independentes" (CUNHA; COELHO, 2009, p. 132). Assim, no contexto deste estudo, a regressão linear múltipla foi utilizada para mensurar a influência do assédio (variáveis independentes), expressa pelos escores fatoriais (3) nos pedidos de remoção (variável dependente). A regressão linear múltipla pode ser expressa pela Fórmula 4 (CUNHA; COELHO, 2009).

$$
Y=\beta_{0}+\beta_{1} x_{1}+\beta_{2} x_{2}+\ldots+\beta_{n} x_{n}+e
$$

Em que Y é a variável dependente; $x_{1}, x_{2}, \ldots x_{\mathrm{n}}$ são variáveis independentes; $\beta_{0}, \beta_{1}, \beta_{2}$, ..., $\beta_{\mathrm{n}}$ são os parâmetros da regressão; e $\varepsilon$ é o termo de erro ou o resíduo da regressão.

\section{APRESENTAÇÃO E DISCUSSÃO DE RESULTADOS}

\subsection{PERFIL DOS ENTREVISTADOS}

A amostra foi composta por brasileiros (98\%), heterogênea quanto ao sexo, porém com leve predominância de mulheres (52\%) sobre homens (48\%). A faixa etária com maior frequência foi de 26 a 41 anos (49\%) e a escolaridade foi elevada entre os entrevistados, posicionando-se na maioria das observações a nível de especialização (35\%). Casados (40\%) e autodeclarados pardos (60\%), os entrevistados foram profissionais ocupantes de cargo efetivos (97\%), na maioria técnico-administrativos (78\%) que não recebiam função gratificada ou cargo de direção (56\%). A experiência profissional posicionou-se nos estratos entre 1 a 5 anos (29\%) e acima de 20 anos de serviço na instituição (33\%), quanto ao local de trabalho, os institutos reuniram quase a metade da amostra (43\%).

\subsection{ANÁLISE FATORIAL EXPLORATÓRIA.}

Os dados foram tratados inicialmente com a análise fatorial exploratória, tendo sido verificada a adequação da matriz de dados. A determinante foi diferente de zero e os testes KMO $(\mathrm{KMO}=0,920)$ e de esfericidade de Bartlett $\left(\chi^{2}=4.853,19\right.$, p-valor=0,000) mostraram valores considerados elevados, aspecto que confirmou o ajustamento da matriz à utilização da análise fatorial. Para determinar o número de fatores, foi utilizado o critério do autovalor, combinando extração pelo método de componentes principais (ACP) e rotação ortogonal Varimax. 
Esses procedimentos possibilitaram sumarizar as 44 variáveis originais em 24, distribuídas em quatro fatores que explicaram $66,05 \%$ da variância dos dados e mostraram consistência interna satisfatória, com coeficientes alphas de Cronbach de 0,912 (Fator 1), 0,882 (Fator 2), 0,863 (Fator 3), 0,859 (Fator 4) e 0,936 para todas as variáveis em conjunto. Assim, os fatores foram considerados fidedignos e sem vieses, conforme os parâmetros mostrados em Kline (1998) e Hair et al. (2009), que consideram adequados alphas de Cronbach superiores a 0,600 e 0,700 (Tabela 1 ).

Tabela 1 Fatores, autovalores, variância explicada e coeficiente alpha de Cronbach

\begin{tabular}{ccccc}
\hline Fator & Número de variáveis & Autovalor & Variância Explicada & Alpha de Cronbach \\
\hline 1 & 7 & 4,68 & 19,52 & 0,912 \\
2 & 6 & 3,97 & 16,53 & 0,882 \\
3 & 6 & 3,96 & 16,50 & 0,863 \\
4 & 5 & 3,24 & 13,50 & 0,859 \\
\hline Total & 24 & 15,85 & 66,05 & 0,936 \\
\hline KMO=0,920, Teste de esfericidade de Bartlett $\left(\chi^{2}\right)=4,853,19$, significante 1\%. & \\
Número de fatores determinados pelo critério do Autovalor. & \\
Extração dos fatores por Análise de Componentes Principais (ACP) e rotação ortogonal pelo método Varimax \\
\hline
\end{tabular}

Fonte: Pesquisa de campo (2019).

Os fatores explicaram a maior parte da variância das variáveis, com comunalidades superiores a 0,553 (Tabela 2). A denominação dos fatores ocorreu pela interpretação semântica das variáveis. Desta forma, o Fator 1 reuniu sete variáveis e foi denominado “Induzir ao erro". O Fator 2, com seis variáveis, foi identificado como "Desqualificar". O Fator 3, também com seis variáveis, foi identificado como "Isolar e recusar de comunicação" e o Fator 4, com cinco variáveis, captou formas de "Violência verbal, física e sexual" e como tal foi denominado.

O primeiro fator, "Induzir ao erro", explicou 19,52\% da variância e, conforme a Tabela 2, reuniu a omissão de informações para a execução das tarefas (V01), a atribuição de quantidade excessiva de trabalho para impossibilitar sua realização com qualidade e no tempo estipulado (V02), o ato de ignorar a presença, dirigindo-se a terceiros para que estes retransmitam a mensagem (V03), a criação de situações que favoreçam erros que possam ser atribuídos ao assediado (V04), o repasse de informações defasadas (V05), a recusa de contato até mesmo visual (V06) além da atribuição de tarefas desprezíveis ou humilhantes (V07). Esse conjunto de ações é habitualmente adotado pelo assediador (HIRIGOYEN, 2000; GUEDES 2008; BARRETO, 2003), com o objetivo de induzir a vítima a erros que possam 


\section{ASSÉDIO MORAL E SEXUAL NO SERVICCO PÚBLICO: CARACTERÍSTICAS E REFLEXOS NOS PEDIDOS DE REMOÇÃO EM UMA INSTITUIÇÃOO DE ENSINO SUPERIOR DA REGIÃO NORTE DO BRASIL DOI: https://doi.org/10.5007/1983-4535.2021.e79018}

ser utilizados ardilosamente para denegrir a imagem profissional e prejudicar até mesmo a autoavaliação profissional do assediado.

Tabela 2 Fatores, variáveis, cargas fatoriais e comunalidades

\begin{tabular}{|c|c|c|c|c|}
\hline Fator & Afirmativa & Variável & $\begin{array}{l}\text { Carga } \\
\text { fatorial }\end{array}$ & $h^{2}$ \\
\hline 1 & $\begin{array}{l}\text { Omitiu deliberadamente informações necessárias para a realização das } \\
\text { tarefas }\end{array}$ & V01 & 0,821 & 0,719 \\
\hline 1 & $\begin{array}{l}\text { Atribuiu a você quantidade excessiva de tarefas, impossibilitando cumpri-las } \\
\text { com qualidade e no prazo. }\end{array}$ & V02 & 0,754 & 0,714 \\
\hline 1 & $\begin{array}{l}\text { Dirigiu-se a terceiros pedindo que eles transmitam a mensagem a você, } \\
\text { mesmo que na sua presença. }\end{array}$ & V03 & 0,741 & 0,675 \\
\hline 1 & Criou situações para favorecer erros que fossem atribuídos a você & V04 & 0,727 & 0,689 \\
\hline 1 & Passou informações defasadas sobre as atividades a serem realizadas & V05 & 0,665 & 0,565 \\
\hline 1 & Recusou qualquer contato com você, até mesmo visual & V06 & 0,656 & 0,671 \\
\hline 1 & Atribui-lhe tarefas desprezíveis ou humilhantes & V07 & 0,650 & 0,629 \\
\hline 2 & Atribuiu a você atitudes agressivas ou desequilibradas & V08 & 0,783 & 0,694 \\
\hline 2 & Fez comentários maliciosos, preconceituosos ou depreciativos sobre você. & V09 & 0,777 & 0,718 \\
\hline 2 & Ocasionou contato físico considerado ofensivo e fez parecer ser acidental & V10 & 0,732 & 0,635 \\
\hline 2 & Demonstrou desinteresse por você ao repassar informações e conteúdos & V11 & 0,682 & 0,657 \\
\hline 2 & $\begin{array}{l}\text { Fez brincadeiras irônicas acerca de alguma dificuldade ou deficiência que } \\
\text { você tenha }\end{array}$ & V12 & 0,659 & 0,574 \\
\hline 2 & Criticou seu trabalho de forma injusta ou exagerada & V13 & 0,625 & 0,607 \\
\hline 3 & $\begin{array}{l}\text { Negou a existência de conflitos ou desentendimentos, mesmo quando eles } \\
\text { eram evidentes. }\end{array}$ & V14 & 0,842 & 0,745 \\
\hline 3 & $\begin{array}{l}\text { Deixou deliberadamente de lhe comunicar eventos promovidos pela } \\
\text { instituição }\end{array}$ & V15 & 0,802 & 0,722 \\
\hline 3 & $\begin{array}{l}\text { Fez proposta de cunho sexual e ofensiva, justificada pela sua aparência física } \\
\text { e disponibilidade. }\end{array}$ & V16 & 0,786 & 0,671 \\
\hline 3 & Excluiu você das atividades realizadas pelas equipes de trabalho & V17 & 0,745 & 0,615 \\
\hline 3 & Insinuou que você fosse inferior aos demais & V18 & 0,742 & 0,652 \\
\hline 3 & $\begin{array}{l}\text { Aumentou deliberadamente o nível de dificuldade das atividades que } \\
\text { caberiam especificamente a você }\end{array}$ & V19 & 0,573 & 0,553 \\
\hline 4 & Agrediu fisicamente (empurrões, puxou algo com agressividade etc.) & V20 & 0,738 & 0,697 \\
\hline 4 & $\begin{array}{l}\text { Fez comentário de cunho sexual ofensivo sobre sua maneira de vestir ou se } \\
\text { comportar }\end{array}$ & $\mathrm{V} 21$ & 0,707 & 0,640 \\
\hline 4 & $\begin{array}{l}\text { Zombou de alguma característica sua (nacionalidade, origem, vida privada } \\
\text { etc.) }\end{array}$ & $\mathrm{V} 22$ & 0,707 & 0,729 \\
\hline 4 & Falou com você gritando & V23 & 0,690 & 0,619 \\
\hline 4 & Insultou-o (a) com termos obscenos e degradantes & V24 & 0,650 & 0,672 \\
\hline
\end{tabular}

Fonte: Pesquisa de campo (2019).

Assim, a vítima do assédio, muitas vezes, não percebe que os erros cometidos foram favorecidos pela ação do agressor. Conforme Hirigoyen (2000) e Guedes (2008), cria-se um ambiente de desconfiança sobre aquele trabalhador. Ele fica estigmatizado como o culpado pelos erros graves nas atividades que desenvolve e acaba impossibilitado de argumentar em sua própria defesa. O agredido pode reagir com cólera aos erros cometidos, sugerindo aos demais um comportamento desequilibrado e agressivo. Nesse sentido, conforme Leyman (1990), Hirigoyen (2000) e Guedes (2008), a vítima passa a achar justo o afastamento imposto 
pelo assediador e a incumbência para a realização de tarefas humilhantes e desprezíveis, uma vez que lhe foram dadas oportunidades de mostrar competência, às quais não respondeu a contento.

O segundo fator, identificado como "Desqualificar", explicou 16,53\% da variância e reuniu, entre as ações assediosas, a atribuição ao assediado de atitudes agressivas ou desequilibradas (V08), comentários maliciosos, preconceituosos ou depreciativos sobre ele (V09), ocasionar contato físico de maneira ofensiva e fazer parecer acidental (V10) e demonstrar desinteresse ao repassar informações (V11).

Ao desqualificar a vítima, o agressor diminui seu potencial de reação, uma vez que a imagem do assediado se fragiliza perante o grupo como consequência de reações agressivas essencialmente desequilibradas e constantemente atribuídas a ele (HIRIGOYEN, 2000; GUEDES; 2008). Reagir aos comentários negativos, depreciativos, maliciosos e carregados de ironia, torna-se cada vez mais difícil, pois ao ser desqualificado perde-se o apoio dos colegas de trabalho ou dos escalões mais elevados da hierarquia organizacional.

Muitas vezes, para desqualificar a vítima, o agressor utiliza o assédio sexual, especialmente para atingir trabalhadores fragilizados, frequentemente mulheres e homossexuais (ORGANIZAÇÃO INTERNACIONAL DO TRABALHO, 2001). Assim, o contato físico ofensivo e constrangedor é justificado como acidental, mas frequente, ocorrendo com a finalidade de criar um ambiente hostil e intimidador (ORGANIZAÇÃO INTERNACIONAL DO TRABALHO, 2001; BRITO, 2011; MORAIS; MÚRIAS; MAGALHÃES, 2014). Assediar sexualmente é também uma das formas de discriminar e desqualificar o assediado (JORNAL DA UNIÃO EUROPÉIA, 2014), pois as queixas são colocadas em dúvida pela percepção distorcida dada pelo agressor.

A desqualificação perpassa pela crítica injusta e exagerada do trabalho, o qual passa por forte vigilância, e pela demonstração de desinteresse no repasse das informações. Para Zabala (2003), nem os colegas e nem o próprio assediado percebem o jogo de desqualificação, uma vez que a falta de confiança na execução das atividades ocorre exclusivamente pela incapacidade de o indivíduo cumpri-las a contento.

O terceiro fator, "Isolar e recusar comunicação", explicou 16,50\% da variância dos dados e captou a negação da comunicação como forma de isolar o assediado. Posicionado entre as formas de assédio moral, o isolamento exprime uma das ações assediosas mais comuns nas relações de trabalho (LEYMAN, 1990; HIRIGOYEN, 2000). Assim, quando o 
assediador interrompe a comunicação com o assediado, ele impossibilita qualquer forma de entendimento e de superação de eventual desavença (MATTOS et al., 2010). O isolamento faz com que a vítima se sinta excluída do grupo, como se não pertencesse mais a aquele ambiente (LEYMAN, 1990). Para Deutschman (1991) e Dias (2008), o isolamento é uma das ações frequentes no assédio sexual (V16), o qual cria um ambiente favorável à passividade de reação às propostas sexuais não desejáveis.

Dificultando o nível das atividades individuais (V19), o assediador impossibilita que assediado as conclua, justificando aos demais a exclusão do assediado das atividades e eventos realizados pela organização no futuro (V15). Alijado da participação nas equipes de trabalho (V17), o assediado se distancia dos demais colegas e, sozinho, sem o apoio dos demais, fica fragilizado. Assim, esse trabalhador passa a se sentir cada vez mais isolado na organização, dada a imagem de inferioridade criada pelo assediador (V18). Hirigoyen (2000) e Guedes (2008) destacam que negar a existência de conflitos (V14) também é uma forma de recusar a comunicação, pois não há o que discutir sobre problemas que só estão supostamente na mente do trabalhador perseguido. Nesse aspecto, o poder exercido pelo assediador sobre o assediado e demais colegas atua de forma direta no comportamento do assediado e na imagem que os outros têm dele (DAHL, 1957; GUIMARÃES; ORGANIZAÇÃO INTERNACIONAL DO TRABALHO, 2001; ZABALA, 2003; CANÇADO; LIMA, 2016). Como resultado, Nunes e Tolfo (2014) ressaltam que o isolamento e a falta de comunicação provocam problemas físicos e psicológicos, além de influenciarem diretamente na demissão ou aposentadoria do trabalhador vítima do assédio.

O quarto fator, "Violência verbal, física e sexual", reuniu comportamentos extremados que mostram as ações do assediador. Estudos de Hulin, Fitzgerald e Drasgow (1996), Fitzgerald et al. (1997), Pryor e Meyers (2000), Willness, Steel e Lee (2007) e de Pina e Page (2015) mostram que a tolerância exacerbada no ambiente organizacional facilita a ocorrência da violência física, verbal e sexual e suas repetições. Heloani e Barreto (2015) destacam que tais violências expressam a habitualidade do agressor e o descontrole da organização sobre seus empregados. Desta forma, em muitos casos, considera-se o fator "Violência verbal, física e sexual" o último estágio de uma série de agressões tidas como de menor gravidade.

Nesse contexto, o assédio ocorre com a utilização de comentários de cunho sexual ofensivo, seja pelo modo de se vestir ou pelo julgamento do modo de se comportar (V21). 
Amplia-se quando ataca a dignidade da pessoa, por meio de gritos (V23) insultos, com a utilização de termos obscenos e degradantes (V24), zomba de alguma característica pessoal (V22) e alcança a violência física pelo descontrole do agressor ao empurrar ou puxar algo com intempestividade (V20). Apesar de esses aspectos ocorrerem com qualquer pessoa, a abordagem erótica de cunho eminentemente sexual é mais comum na abordagem as mulheres (COSTA, 1995; ORGANIZAÇÃO INTERNACIONAL DO TRABALHO, 2001; PINA; PAGE, 2015; BENDIXEN; KENNAIR, 2017).

\subsection{REGRESSÃO LINEAR MÚLTIPLA.}

Após a análise fatorial, foi utilizada a regressão linear múltipla (RLM) para analisar a incidência do assédio moral e sexual nos pedidos de remoção e, com isso, identificar relações de dependência entre as variáveis em estudo. Foi utilizado o método Backward, tomando como variável dependente (VD) a assertiva "Já troquei de departamento por ter sofrido alguma forma de assédio" e como variáveis independentes (VI) os valores dos escores fatoriais. Os escores (VI) foram significativos a $1 \%$ e os resultados da regressão estão apresentados na Tabela 3 .

Tabela 3 Regressão linear múltipla para a influência do assédio nos pedidos de remoção

\begin{tabular}{lccccc}
\hline Variável Dependente (VD): Já troquei de departamento por ter sofrido alguma forma de assédio & \\
\hline Variáveis Independentes & Coeficientes & Desvio Padrão & Teste T & P-valor & VIF \\
\hline Constante & 5.087649 & 0.176027 & 28.90263 & 0.0000 & \\
F1 - Induzir ao erro & 0.773514 & 0.176379 & 4.385524 & 0.0000 & 1,00 \\
F2 - Desqualificar & 0.781346 & 0.176379 & 4.429928 & 0.0000 & 1,00 \\
F3 - Isolar e recusar comunicação & 0.527037 & 0.176379 & 2.988092 & 0.0031 & 1,00 \\
F4 - Violência física, verbal e sexual & 0.767304 & 0.176379 & 4.350315 & 0.0000 & 1,00 \\
\hline R-quadrado & 0.213331 & VD Média & 5.0988 & \\
R-quadrado ajustado & 0.200540 & VD Desvio padrão & 3.1190 & \\
Teste F & 16.67775 & Estatística D & 1.6916 & \\
P-valor (Teste F) & 0.000000 & Teste Breuch-Pagan-Godfrey $(1,1256$, p-valor $=0,3449)$ \\
\hline Teste Jaque-Bera $(2,1297$, p-valor $=0,3447)$
\end{tabular}

Fonte: Pesquisa de campo (2019).

Os pressupostos da regressão linear múltipla (RLM) foram investigados e atendidos. O Teste F (significativo a 1\%) mostrou que pelo menos uma das variáveis independentes (VI) era capaz de influenciar a variável dependente (VD). Os resíduos tiveram distribuição normal e independente conforme o teste Jaque-Bera ( $p$-valor=0,3447). Houve ausência de multicolinearidade, atestada pela estatística VIF com valores unitários $(1,00)$ para todas as variáveis independentes (VI), aspecto esperado a priori, visto os escores rotacionados com 
Varimax serem naturalmente ortogonais, tendo sido constatada ausência de heterocedasticidade pelo teste Breuch-Pagan-Godfrey (p-valor=0,3449).

A estimação do modelo, com r-quadrado ajustado de $20 \%$, mostrou poder explicativo adequado para pesquisas sociais e que os pedidos de remoção podem, em parte, ser explicados pelo assédio moral e sexual. Observa-se que a média da variável dependente em 5,09 $( \pm 3,12)$, próxima ao centro da escala $(5,50)$, indica intensidade intermediária do assédio nas solicitações de mudança de departamento. Quanto às variáveis independentes (VI), os coeficientes positivos e significativos a $1 \%$ mostram que o modelo é coerente e que as variáveis independentes influenciam no desejo de remoção. Desta forma, observa-se que induzir ao erro (F1), desqualificar (F2), isolar e recusar a comunicação (F3) e praticar alguma forma de violência, física, verbal ou sexual (F4) são elementos que levam a pedidos de remoção.

Para Mattos et al. (2010), o ato de marginalizar o trabalhador, afastando-o de suas atividades habituais, objetiva diminuir gradativamente sua satisfação com o trabalho, forçando-o a se afastar do ambiente ou até mesmo a pedir remoção. Nesse sentido, a organização que não combate os comportamentos assediosos compromete a equipe de trabalho pela perda de capital intelectual, uma vez que o trabalhador que deixa a organização carrega consigo os conhecimentos e experiências adquiridos, além de fomentar ações cada vez mais agressivas, criando um ambiente de medo e tensão no trabalho.

No serviço público, o assediador, muitas vezes, se mostra mais agressivo em decorrência da impossibilidade ou da maior dificuldade para a demissão da vítima. Assim, comumente o servidor pede remoção e, mesmo quando atendido, corre o risco de ter sua reputação comprometida na organização (HIRIGOYEN, 2006; MATTOS et al., 2010). Para Einarsen, Nielsen e Glaso (2017), o assédio no local de trabalho provoca um ambiente insustentável para a vítima, que não vê outra solução que não sua saída.

\section{CONSIDERAÇÕES FINAIS}

Esta pesquisa possibilitou caracterizar as formas de assédio moral em quatro fatores, ou variáveis latentes, que explicaram a maior parte da variância dos dados e foram identificadas como "Induzir ao erro" (Fator principal), "Desqualificar", "Isolar e recusar comunicação" e "Violência verbal, física e sexual". Essa composição de fatores mostra o processo espiral que caracteriza o assédio e que normalmente é iniciado de forma velada, 
induzindo o assediado a erro, possibilitando, assim, desqualificá-lo perante os demais colegas de trabalho e junto aos níveis mais elevados da hierarquia organizacional. Enfraquecido e sozinho, por ser considerado incompetente e prejudicial ao grupo, ele fica progressivamente mais isolado dos demais. Por outro lado, a interrupção da comunicação nega qualquer possibilidade de entendimento com o agressor, o que poderia interromper os ataques e restauram um ambiente mais equilibrado de trabalho. Nesse momento, sozinho e fragilizado, ele se torna uma presa fácil para o assediador. Já na fase final, o agressor não se preocupa mais em esconder suas intenções e parte para ações declaradas, como agressões verbais, violência física e assédio sexual.

Os resultados mostraram que todos os fatores identificados no estudo foram capazes de influenciar nos pedidos de remoção, confirmando a relação de dependência. Os resultados mostraram que o assédio influenciou em $20,71 \%$ dos pedidos de movimentação interna, que ocorreram a pedido dos servidores. Esse aspecto confirma a associação positiva entre o assédio moral e a necessidade de deixar o departamento ou a seção e, com isso, fugir do agressor, o que reforça a necessidade de ações de combate à violência laboral como uma estratégia para proporcionar um ambiente de trabalho mais saudável, construtivo e produtivo. Entre as limitações desse estudo, destaca-se que ele não alcançou os servidores que pediram exoneração ou redistribuição para outras instituições, nem outros campi além da sede da universidade, o que pode representar sugestões para pesquisas futuras, assim como, mostramse oportunas novas investigações de caráter qualitativo para investigar o fenômeno em maior profundidade.

\section{REFERÊNCIAS}

BARRETO, M. M. S. Assédio moral no trabalho: uma odisseia de sofrimento e incertezas. In: NUNES SOBRINHO, F. P.; NASSARALLA, I. (Org.). Pedagogia institucional: fatores humanos nas organizações. Rio de Janeiro: Zit, 2004.

BARRETO, M. M. S. Uma jornada de humilhações. 2000. 266 f. Dissertação (Mestrado em Psicologia Social), Pontifícia Universidade Católica, São Paulo, 2000.

BARRETO, M. M. S. Violência, saúde e trabalho: uma jornada de humilhações. São Paulo: EDUC, 2003.

BENDIXEN, M.; KENNAIR, L. E. O. Advances in the understanding of same-sex and opposite-sex sexual harassment. Evolution and Human Behavior. Reino Unido, v. 38, n. 5, p. 583-591, set. 2017. 
BRASIL. Decreto-lei, no. 2.848 de 7 de dezembro de 1940. Código Penal. Disponível em: < http://www.planalto.gov.br/ccivil_03/decreto-lei/Del2848.htm>. Acesso em: 2 nov. 2018.

BRASIL. Lei no. 10.224, de 15 de maio de 2001.

Altera o Decreto-Lei no 2.848 , de 7 de dezembro de 1940 - Código Penal, para dispor sobre o crime de assédio sexual e dá outras providências. Disponível em:

$<$ http://www.planalto.gov.br/ccivil_03/leis/LEIS_2001/L10224.htm>. Acesso em: 2 nov. 2018 .

BRITO, M. P. O assédio moral e o assédio sexual no âmbito da administração pública competência material da Justiça do Trabalho. Rev. Trib. Reg. Trab. $3^{\mathbf{a}}$ Reg., Belo Horizonte, v.54, n.84, p.219-236, jul./dez. 2011.

BRODOSKY, C. M. The harassed worker. Oxford England: Heath \& Corporation, 1976.

BURGES, D.; BORGIDA, E. Refining sex-role spillover theory: The role of gender subtypes and harasser attributions. Social Cognition, v. 15, n. 4, p. 291-311, dec. 1997.

CARAN, V. C. S et al. Assédio moral entre docentes de instituição pública de ensino superior do Brasil. Acta Paul. Enferm. São Paulo, v. 23, n. 6, p. 737-744, nov./dez. 2010.

CHAMBERLAIN, L. J. et al. Sexual harassment in organizational context. Work and Occupations, v. 35, n. 3, p. 262-295, ago. 2008.

COSTA, I. C. P. et al. Produção científica acerca do assédio moral em dissertações e teses no cenário brasileiro. Revista da Escola de Enfermagem da Universidade de São Paulo, São Paulo, v. 49, n. 267-276, nov. 2015.

COSTA, S. O assédio sexual nos locais de trabalho: problemas e possíveis soluções através de estudo de casos. 1995. 149 f. Dissertação (Mestrado em Administração), Universidade Federal do Rio Grande do Sul, Porto Alegre, 1995.

CUNHA, J. V. A.; COELHO, A. C. Regressão linear múltipla. In: CORRAR, L. J.; PAULO, E.; DIAS FILHO, J. M. Análise multivariada. São Paulo: Atlas, 2009.

DAHL. R. The concept of power. Systems Research Behavioral Science. v.2. n. 3, p. 2012015, jul. 1957.

DEUTSCHMAN, A. Dealing with sexual harassment. Fortune, v. 124, n. 11, p. 93-94, nov. 1991.

DIAS, I. Violência contra as mulheres no trabalho: o caso do assédio sexual. Sociologia: problemas e práticas, n. 57, p. 11-23, maio. 2008.

DILLON, W. R.; GOLDSTEIN, M. Multivariate analysis: methods and applications. New York, John Wiley \& Sons, 1984. 
EINARSEN, S.; NIELSEN, M. B; GLASØ, L. Exposure to workplace harassment and the Five Factor Model of personality: a meta-analysis. Personality and Individual Differences, v. 104, p. 195-206, jan. 2017.

FITZGERALD, L. et al. Antecedents and Consequences of Sexual Harassment in Organizations: a Test of an Integrated Model. Journal of Applied Psychology, v. 82, n. 4, p. 578-589, 1997.

FITZGERALD, L.; ORMEROD, A. J. Perceptions of sexual harassment: The influence of gender and academic context. Psychology of Women Quarterly, v.15, n. 2, p. 281-294, aug. 1991.

FREITAS, M. E. Assédio moral e assédio sexual: faces do poder perverso nas organizações. Revista de Administração de Empresas, São Paulo, v.41, n.2, p.8-19, abr./jun., 2001.

FREITAS, M. E. Existe saúde moral nas organizações? Organizações \& Sociedade, Salvador, v.12, n. 32, p. 13-27, jan-mar. 2005.

FREITAS, M. E. Quem paga a conta do assédio no trabalho? RAE, São Paulo, v. 6, n. 1, jan. /jun. 2007.

GIL, A. C. Métodos e técnicas de pesquisa social. São Paulo: Atlas, 2014.

GUEDES, M. N. Terror psicológico no trabalho. São Paulo: LTr Editora, 2008.

GUIMARÃES, C. A.; CANÇADO, V. L.; LIMA, R. J. C. Workplace moral harassment and its consequences: a case study in a federal higher education institution. Revista de Administração. São Paulo, v. 51, n. 2, p. 151-164, abr./jun. 2016.

HAIR JR J. F. et al. Análise multivariada de dados. Porto Alegre: Bookman, 2009.

HELOANI, J. R. M. Assédio moral: um ensaio sobre a expropriação da dignidade no trabalho. RAE, São Paulo, v 3. n.1, p. 1-8, jan. /jun. 2004.

HELOANI, J. R. M.; BARRETO, M. M. S. Assédio moral nas relações sociais no âmbito das instituições públicas. In: GEDIEL, J. A. P. et al. (Eds.). Estado, poder e assédio: relações de trabalho na administração pública. Curitiba: Kairós Edições, 2015.

HERZBERG, F. I. Maximizing work and minimizing labor. Industry Week, v. 206, n. 8, p. 61-64, oct. 1980 .

HERZBERG, F. I. Les quatre questions existentielles: leur effet sur la motivation humaine et le comportement organisationnel. In: PAUCHANT, T. C. et al. (Coord.). La quête du sens: gérer nos organisations pour la santé des personnes, de nos sociétés et de la nature. Québec: Éditions de l'organisation, 1996. .

HERZBERG, F. I. Work and the nature of man. Cleveland: World Publishing Co., 1966. 
HIRIGOYEN, M. Assédio moral. Rio de Janeiro: Bertrand Brasil, 2000.

HIRIGOYEN, M. Mal-estar no trabalho: redefinindo o assédio moral. Rio de Janeiro: Bertrand Brasil, 2006.

HULIN, C. L.; FITZGERALD, L. F.; DRASGOW, F. Organizational influences on sexual harassment. In: STOCKDALE, M. S. (Ed.). Sexual harassment in the workplace: Perspectives, frontiers and response strategies. Thousand Oaks, CA: Sage, 1996.

JORNAL DA UNIÃO EUROPÉIA. 21.12.2004. L373/37-43. DIRECTIVA 2004/113/CE DO CONSELHO de 13 de dezembro de 2004 que aplica o princípio de igualdade de tratamento entre homens e mulheres no acesso a bens e serviços e seu fornecimento. Disponível em: <http:/www.cite.gov.pt/imgs/directivas/Directiva\%202004-113.pdf>. Accesso em: 12 de out. 2018.

KLINE, R. B. Principles and practice of structural equation modeling. New York: The Guilford Press, 1998.

LEYMANN, H. Mobbing and psychological terror at workplace. Violence and Victims, v. 5, n.2, p. 119-126, 1990.

LEYMANN, H. The content and development of Mobbing at work. European Journal of Work and Organizational Psychology, v. 5, n. 2, p. 165-84, jan.1996.

MATTOS, C. A. C. et al. O assédio moral no serviço público estadual: uma investigação no Estado do Pará. Revista Brasileira de Gestão e Desenvolvimento Regional. São Paulo, v. 6, n. 3. p. 50-71, set./dez. 2010.

MEJÍAS GARCIA, A. M. EI acoso sexual en el trabajo: análisis y propuestas para su prevención. Espanha: Valência, 2001.

MORAIS, T.; MÚRIAS, C.; MAGALHÃES, M. J. Assédio sexual no trabalho: uma reflexão a partir de ordenamentos jurídicos. International journal on working conditions, Porto, $\mathrm{n}$. 7, jun., 2014.

NÓBREGA. M. F. S. As percepções de assédio sexual. 2016. 67 f. Dissertação (Mestrado em Psicologia) - Universidade do Porto, Portugal, 2016.

NUNES, T. S.; TOLFO, S. R. Assédio moral no trabalho em universidade sob a perspectiva dos observadores da violência. RECAPE: Revista de Carreira e Pessoas, v. 4, n. 2, p. 166176, mar./ago. 2014.

ORGANIZAÇÃO INTERNACIONAL DO TRABALHO. Discriminação no Trabalho: Mecanismos de Combate à Discriminação e Promoção de Igualdade de Oportunidades: Repertório de recomendações práticas da OIT sobre HIV/AIDS e o mundo do trabalho. Oficina Internacional del Trabajo. Brasília: Secretaria Internacional do Trabalho, 2001 . 
PIERUCCI, S. et al. Creating shared reality about ambiguous sexual harassment: The role of stimulus ambiguity in audience-tuning effects on memory. Journal of Applied Research in Memory and Cognition. Reino Unido, v. 3, n.4, p. 300-306, dec. 2014.

PINA, A.; PAGE, T. E. Moral disengagement as a self-regulatory process in sexual harassment perpetration at work: A preliminary conceptualization. Aggression and Violent Behavior, Reino Unido, v. 21, p. 73-84, jan 2015.

PRYOR, J. B.; MEYERS, A. B. Men who sexually harass women. In: SCHLESINGER, L. B. (Ed.). Serial offenders: Current thought, recent findings, unusual syndromes Florida: CRC Press, 2000.

WILLNESS, C. R.; STEEL, P.; LEE, K. A meta-analysis of the antecedents and consequences of workplace sexual harassment. Personnel Psychology, n. 60, n. 1, p. 127162. feb. 2007.

ZABALA. I. P. Mobbing: como sobreviver ao assédio psicológico no trabalho. São Paulo: Edições Loyola, 2003. 